\title{
Editorial August 2013
}

Jan Turek, University of Hradec Králové, Rokitanského 62, 50003 Hradec Kralove, Czech Republic

E-mail: turekjan@hotmail.com

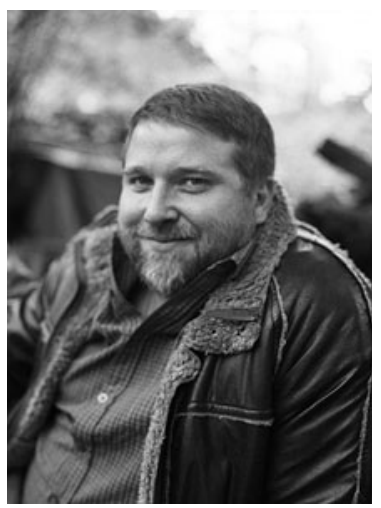

This volume brings together papers on different issues of Palestinian cultural heritage. It is one of the important intention of Archaeologies to maintain the plural discussion on different archaeology and heritage issues especially in the regions where diverse perception of past divides people into different ethnical or religious groups.

Currently there are almost 11 million of Palestinians living in different parts of the World; however, only 4 million of them are living within the Palestinian territories. The Palestinian population is also very young: over one-third of the population comprises children. This new generation of Palestinians deserves to read the modern explanation of their nation's history that needs to be free as their new independent country. While discussing the liberty of cultural heritage reconstruction and interpretation, we have to bear in mind what John Stuart Mill had already said in 1859 that "your liberty ends where the liberty of others begins." In Archaeologies, we assert the freedom of speech for the mainstream communities, as well as, for the minorities, for nations great or small. In the current globalized World, there are many different communities and ethnical or religious groups that struggle for their identity and freedom. The free discussions on the heritage issues and shared identities are often creating an intellectual 
background for the approximation of political opinions and important basis for the future understanding between unfriendly or competing communities.

Unfortunately, there are regions, such as present day Syria, where people abandoned the opportunity of discussion and turned to sectarian violence damaging not only the cultural heritage of their ancestors but also lives of their contemporaries. Also under such dreadful circumstances, archaeologists are obliged to act. The fighting against such destruction of human values is not only up to those brave of us who under the shelter of Blue Shield rescue the vandalized heritage, but it is the task for all archaeologists to go public with information on such atrocities to influence the public opinion worldwide to stop and prevent such senseless destruction of the World heritage.

As the 1989 student activist of the Czechoslovak Velvet revolution, I was always substantially engaged in the struggle for human rights including the right for the autonomous and liberal reading and writing of human history. For this reason, the position of new coming co-editor of Archaeologies is for me a great opportunity to maintain the pluralism of free and fair discussion on different issues of World archaeology regardless of the political background of its actors. Together with Cristóbal Gnecco, we are looking forward to meeting you on pages of future volumes of Archaeologies sharing our passion for the past of human societies. 